\title{
Spontaneously resolving unilateral ophthalmoplegia with paralytic proptosis of idiopathic origin
}

\author{
ALY MORTADA \\ Department of Ophthalmology, Faculty of Medicine, Cairo University
}

Idiopathic unilateral ophthalmoplegia with paralytic proptosis which recovered spontaneously in I to 2 months has been attributed to transient myositis (Dunnington and Berke, I943; Babel, I 947); to serous tenonitis causing myositis (Ferrall, I 841 ; Duke-Elder, I949); to periostitis of the superior orbital fissure (Collier, I92 I); to neuritis of the peripheral ocular nerves (von Graefe, r866; Landesberg, r88o; Uhthoff, I 886; Suckling, r 886; Wilson, 192 I); and to blood cyst from an angiomatous malformation (Mortada, I96I, 1969) pressing on the ocular nerves in the region of the superior orbital fissure.

The incidence of such causes in six cases of unilateral ophthalmoplegia in children was studied in two ways:

(I) Tiny biopsies of the affected extraocular muscles and Tenon's capsule were examined histologically;

(2) The apex of the orbit was explored with the little finger.

\section{Case reports}

In these six cases of unilateral ophthalmoplegia with proptosis, the general, ocular, rhinological, and neurological investigations were negative. The clinical features are shown in the Table and illustrated in Figs I-Io (overleaf).

Table Clinical data for six cases of spontaneously resolving unilateral ophthalmoplegia with paralytic proptosis of idiopathic origin

\begin{tabular}{|c|c|c|c|c|c|c|}
\hline $\begin{array}{l}\text { Case } \\
\text { no. }\end{array}$ & Sex & Age (yrs) & $\begin{array}{l}\text { Side } \\
\text { affected }\end{array}$ & Ptosis & $\begin{array}{l}\text { Internal } \\
\text { ophthalmoplegia }\end{array}$ & $\begin{array}{l}\text { Duration before } \\
\text { resolution (mths) }\end{array}$ \\
\hline $\mathbf{I}$ & $\mathbf{M}$ & (Figs I and 2) & Left & Present & Absent & 2 (Fig. 3) \\
\hline 2 & $\mathbf{M}$ & ${ }^{7}$ (Figs 4 and 5) & Right & Present & Pupil dilated & 2 \\
\hline 3 & $\mathbf{M}$ & $\stackrel{4}{(\text { Figs } 6}$ and 7) & Right & Present & Absent & $1 \frac{1}{2}$ \\
\hline 4 & $\mathbf{M}$ & (Fig. 8) & Right & Present & Absent & I $\frac{1}{2}$ \\
\hline 5 & $\mathbf{M}$ & (Fig. 9) & Right & Absent & Absent & I \\
\hline 6 & $\mathbf{M}$ & 3 & Left & Absent & Absent & I \\
\hline
\end{tabular}




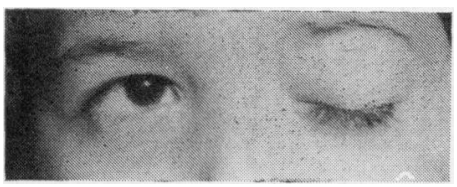

FIG. I Left idiopathic total external ophthalmoplegia with proptosis of I week's duration in a 5-year-old boy (Case I)

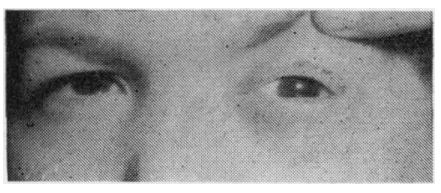

FIG. 2 Left upper lid elevated to show proptosis (Case I)

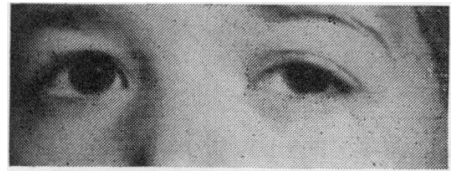

FIG. 32 months later showing complete spontaneous resolution (Case 1)

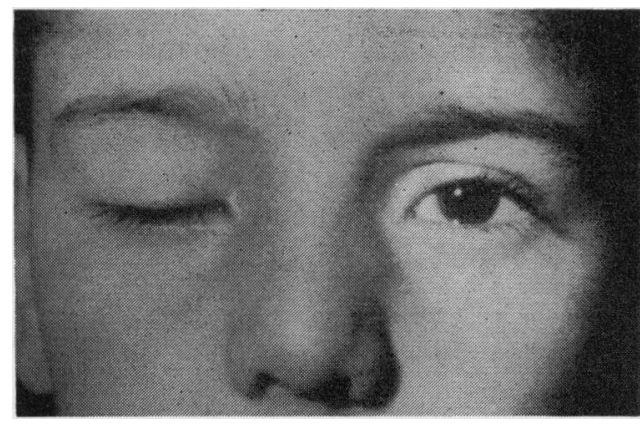

FIG. 4 Right idiopathic total ophthalmoplegia with proptosis of 5 day's duration in a 7-year-old boy (Case 2)

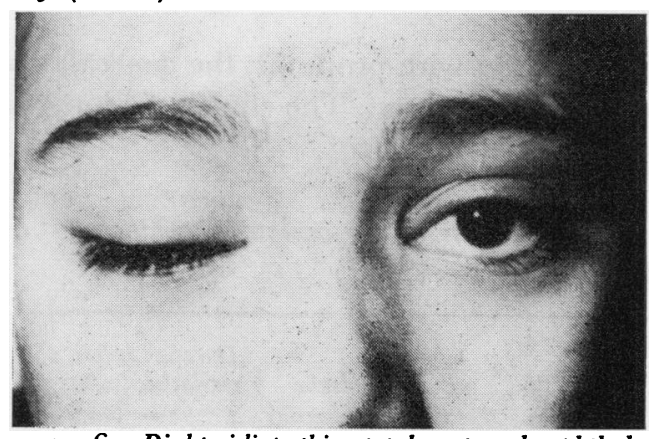

FIG. 6 Right idiopathic total external ophthalmoplegia with proptosis of 6 day's duration in a 4-year-old boy (Case 3)

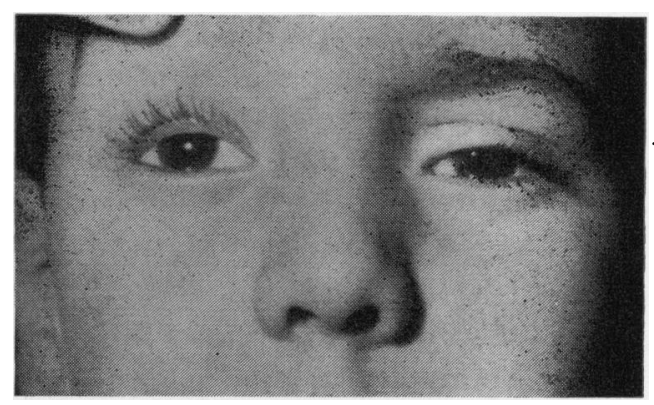

F IG. 5 Right upper lid elevated to show proptosis (Case 2)

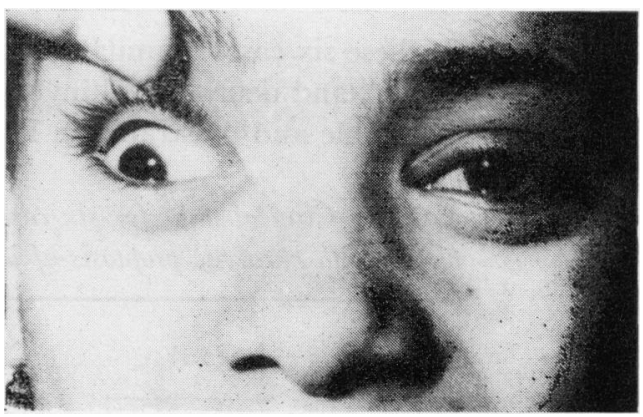

FIG. 7 Right upper lid elevated to show proptosis (Case 3)

Unilateral ocular nerve affection with proptosis developed quickly with varying degree of headache, pain in the eye, and neuralgia of the forehead on the affected side. The condition did not date from birth. There was no history of head trauma, exposure to cold, strain, migraine, syphilis, or rheumatic pain. The patients were not taking drugs as barbiturates to cause intoxication. There was no recent history of fever, diphtheria, influenza, measles, smallpox, typhoid, typhus, mumps, malaria, whooping cough, septicaemia, cerebrospinal meningitis, poliomyelitis, or encephalitis, or of neurological disease or loss of consciousness. 


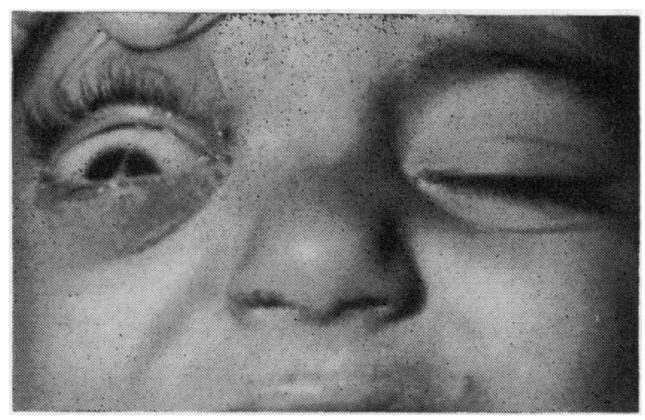

FIG. 8 Right idiopathic total external ophthalmoplegia with proptosis of 8 day's duration in a 2-year-old boy (Case 4)

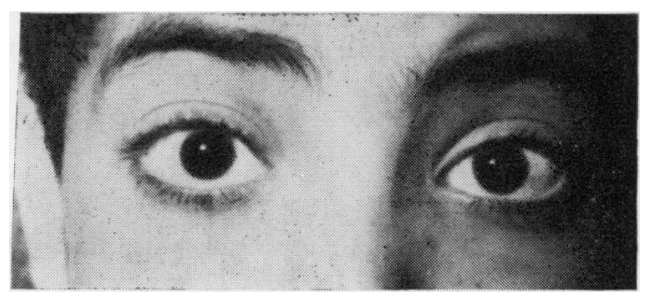

FIG. 9 Right idiopathic partial external ophthalmoplegia (no ptosis) with proptosis of 2 week's duration in a 5-year-old boy (Case 5)

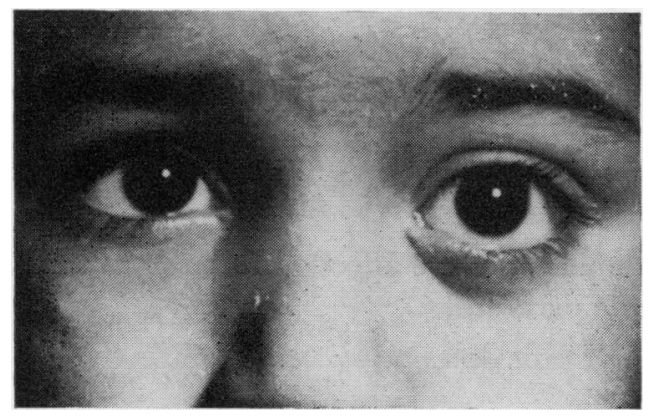

FIG. Io Left idiopathic partial external ophthalmoplegia (no ptosis) with proptosis of one week's duration in a 3-year-old boy (Case 6)

The patients' general health was perfect. There were no signs of vitamin deficiency, and no allergic or hysterical manifestations. The skin of the face did not show any boils or herpetic eruptions. There was no enlargement of the parotid, lacrimal, thyroid, or lymph glands, and no malignant tumour in the body. The temperature, blood pressure, pulse, and heart were normal. The chest did not reveal any tuberculous lesion. There were no foci of infection such as septic teeth, etc. The tonsils and nasal sinuses were normal with no signs of otitis media or nasopharyngeal tumours.

Apart from the unilateral ophthalmoplegia there was no other neurological manifestation. The motor and sensory systems, reflexes, and sphincters were normal. There was neither subjective nor objective evidence of increased intracranial pressure or any endocrine or trophic changes. The clinical test for myasthenia gravis was negative and there was no lethargy. There was no sign of disseminated sclerosis after prolonged observation.

There was no oedema of the lids or chemosis of the conjunctiva or signs of inflammation of Tenon's capsule or sclera to account for an acute orbital inflammation; and no subconjunctival haemorrhage or lid ecchymosis. There were no fundus changes, nystagmus, or palpable orbital mass.

The urine was free of sugar, acetone, and albumin. The stools were negative for parasites. The blood Wassermann reaction was negative. The haemoglobin percentage, blood counts, erythrocyte sedimentation rate, blood sugar curve, bleeding and clotting 
times were normal. The Mantoux test was negative. The cerebrospinal fluid, pressure, cells, proteins, and salt were normal.

The lateral $x$ ray of the skull showed no changes in the sella turcica or clinoid processes or any suprasellar calcification. A postero-anterior view with $20^{\circ}$ tube tilt showed no change in the bony margin of the superior orbital fissure or in the lesser or great wing of the sphenoid bone. The nasal sinuses were normal. Right and left oblique views showed normal optic canals. A view of the base of the skull showed no abnormality. The nasopharynx showed no abnormality. Lateral and postero-anterior angiograms showed no abnormality.

The orbital apex was explored by a lateral transconjunctival orbitotomy. Little finger palpation and histological examination of tiny parts of the affected extraocular muscles and adjacent Tenon's capsule removed at biopsy revealed no change which could account for the condition.

\section{Conclusions and Summary}

Six cases of spontaneously resolving unilateral ophthalmoplegia with paralytic proptosis of idiopathic origin were examined.

(I) All the cases occurred in male children.

(2) The degree of ophthalmoplegia varied and in some cases there was no ptosis or internal ophthalmoplegia.

(3) Exploration of the orbital apex was negative.

(4) Biopsy did not reveal myositis or tenonitis.

(5) The most probable site for this multiple nerve affection is the superior orbital fissure, perhaps through transient non-specific periostitis.

(6) Recovery can be hastened by oral salicylates or corticosteroids.

\section{References}

BABEL, J. (1947) Ophthalmologia (Basel), I14, 312

collier, J. (I92 I) Proc. roy. Soc. Med., r4 (Sect. Neurol. Ophthal., p. Io)

DUKE-ELDER, S. (1949) "Text-book of Ophthalmology", vol. 4, p. 4138. Kimpton, London

Dunnington, J. H., and Berke, R. N. (1943) Arch. Ophthal. (Chicago), 30, 446

FERRALl, J. M. (1841) Dublin J. med. Sci., r9, 343

GRAEFE, A. VON (1866) v. Graefes Arch. Ophthal., 12 (2), 265

landesberg, M. (1880) Med. Bull. Philad., 2, 108

MORTADA, A. (196r) Brit. 7. Ophthal., 45, 662 (1969) Ibid., 53, 398

suCKLING, c. w. (1886) Brit. med. 7., 1, 253

UHTHOFF, W. (1886) Berl. klin. Wschr., 23, 54

Wilson, s. A. KINNIER (I921) Brit. J. Ophthal., 5, 349 